\title{
A POLÍTICA INTERNACIONAL DE JK E SUAS RELAÇ̃̃es PERIGOSAS COM O COLONIALISMO PORTUGUÊS
}

\author{
Waldir José Rampinelli* \\ Depto de História/UFSC
}

Resumo: $\mathrm{O}$ artigo analisa o apoio político dado por Juscelino Kubitschek à manutenção do colonialismo português. O Brasil defendeu, na Quarta Comissão da ONU, a tese de que Portugal não dispunha de colônias, mas sim de províncias ultramarinas. Diante deste quadro, o artigo aponta as razões que levaram JK a dar suporte político ao império colonial lusitano.

Palavras-chave: Juscelino Kubitschek ; política internacional ; colonialismo.

\section{The international JK politic and its dangerous relationships with the portuguese colonialism}

\begin{abstract}
This article analyses the political support gave by Juscelino Kubitschek for the maintenance of Potuguese's colonialism. In the fourth UN Commission, Brazil defended, about political aspect, the thesis that Portugal doesn't dispose of colonies but provinces beyond the sea. So in this sense, this article analyses the reasons why JK supported the Potuguese's colonialism.
\end{abstract}

Key Words: Juscelino Kubitschek ; international politic; colonialism.

Juscelino Kubitschek, ao longo de seu governo (1956/1961), adotou uma política internacional de apoio ao império colonial português. "Tocar em Portugal era tocar no Brasil”, afirmava Donatello Grieco, representante brasileiro na Quarta Comissão da ONU onde se travava o debate sobre colonização. O delegado indiano R. Jaipal, depois de escutar a defesa do diplomata Grieco proclamando a missão civilizadora de Portugal no além-mar, disse que "nunca ouvira uma exposição mais fiel ao ponto de vista português do que aquela que acabara de fazer o representante do Brasil". Neste artigo, analisarei a política internacional de JK com Portugal e as razões de seu apoio ao colonialismo.

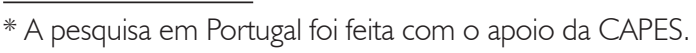




\section{O Tratado de Amizade e Consulta}

As relações de apoio do governo brasileiro ao português se materializam com a assinatura do Tratado de Amizade e Consulta, em 16 de novembro de 1953. Nele, se dá forma jurídica à comunidade luso-brasileira. Esse tratado é o resultado de todo um esforço que começa por volta de 1917, quando Bettencourt Rodrigues mais tarde ministro dos Negócios Estrangeiros - defende a criação da Confederação Luso-brasileira. A obra de Gilberto Freyre contribui para mudar o conceito do português conquistador e, por ocasião das comemorações do VIII Centenário da Fundação e III da Restauração da Independência, ambos os eventos de Portugal, respectivamente nos anos 1939 e 1940, aumenta-se o clima de aproximação entre os dois países. Durante os anos de 1940 e 1950, João Neves da Fontoura, um conhecido lusófilo ${ }^{1}$, ocupou os cargos de embaixador em Lisboa e ministro das Relações Exteriores no Rio de Janeiro, respectivamente. A sua participação foi fundamental para que as negociações referentes ao Tratado de Amizade e Consulta avançassem e fossem concluídas, tendo sido finalmente assinado no governo de Getúlio Vargas, ratificado no de Café Filho e regulamentado no de Juscelino Kubitschek.

Por outro lado, a diplomacia portuguesa se empenhou com afinco na elaboração do Tratado de Amizade e Consulta, utilizando diversos mecanismos para moldar tanto a sua forma quanto o seu conteúdo. O embaixador António Faria, em ofício confidencial ao ministro dos Negócios Estrangeiros, narra o caminhar das negociações e diz que "de qualquer maneira não será indiferente que num instrumento diplomático se estabeleça que os portugueses devem ter no Brasil um tratamento especial, diferente do regime comum, que os equipare aos nacionais, mesmo com a restrição das disposições constitucionais em contrário. $\mathrm{E}$ pede prudência, no artigo $6^{\circ}$, no que se refere aos territórios ultramarinos, afim de que seja limitado o seu alcance". ${ }^{2}$

Embora o Tratado de Amizade e Consulta tivesse como objetivo fundamental harmonizar as políticas externas dos dois países, foi largamente utilizado pela diplomacia portuguesa como mecanismo de pressão no apoio à manutenção de suas colônias. José Honório Rodrigues chegou a afirmar que "o Tratado é uma vitória portuguesa, arrastando o Brasil para a sua órbita (...), visando a dispor de nosso apoio nas suas dificuldades internacionais ${ }^{3}$

Na realidade, como Portugal não fazia parte das Nações Unidas quando da assinatura do Tratado de Amizade e Consulta, ressentia de um governo que o defendesse nessa organização. Com esse instrumento jurídico em vigência, o Brasil não só passou a apoiar os interesses portugueses com mais afinco, como também os lusófilos do Itamaraty sentiram-se respaldados para formular uma política externa em favor da metrópole colonialista. Além do mais, como o Tratado afirmava que 
ambos os países "se consultarão sempre sobre os problemas internacionais de seu manifesto interesse comum", a experiente diplomacia portuguesa passava a se manter a par da política externa brasileira, tendo ao seu alcance um excelente instrumento para desmantelar as iniciativas dos nacionalistas ${ }^{4}$ que pregavam o fim do colonialismo.

Chegou a haver, por parte de alguns diplomatas brasileiros, declarações subservientes na imprensa defendendo os interesses portugueses. Vasco Leitão da Cunha, por exemplo, embaixador do Brasil na Bélgica, afirmou que "não seria mesmo fora de propósito dizer-se que, acima do tratado de amizade e de consulta assinado pelos nossos dois países, todo o brasileiro é um Português honorário (...) Atrevo-me mesmo a dizer que, se não fosse a estreiteza de vistas do parlamento de Lisboa em 1822, que queria a todo custo reduzir de novo o Brasil ao estatuto de colônia, nós viveríamos talvez ainda hoje no Reino Unido de Portugal e do Brasil". 5

\section{JK e o colonialismo português}

JK, que em janeiro de 1956 empreendera uma viagem aos Estados Unidos e à Europa ainda na condição de presidente eleito, chegou a Lisboa no dia 22 e foi recebido como chefe-de-Estado. Como o litígio entre Portugal e a União Indiana havia se agudizado, a imprensa lusitana quis saber de Kubitschek sua posição política sobre o conflito, ao que ele afirmou que "o meu governo vai aumentar a solidariedade com Portugal no caso de Goa e em todos os terrenos". ${ }^{6}$

Essa afirmativa de Kubitschek foi um deslize diplomático, já que naquele momento o Brasil representava os interesses portugueses na Índia devido à ruptura de relações diplomáticas entre os dois países. Tanto que o governo indiano atribuiu "grande gravidade" a tais declarações e pretendia apresentar uma nota de protesto na embaixada brasileira em Nova Delhi.

Com relação à questão do café - que preocupava muito os produtores brasileiros -, Juscelino manifestou-se partidário de negociações multilaterais, nas quais todas as partes pudessem sentir-se satisfeitas, embora considerasse que, "no caso especialíssimo de Portugal, as soluções para os problemas econômicos" deviam ser "subordinadas aos imperativos de ordem política". Essa era uma posição francamente favorável aos interesses portugueses que competiam vantajosamente, em nível internacional, com o café brasileiro. Tanto que mais tarde aumentariam as críticas aos concorrentes africanos, e obviamente a Portugal, nos jornais brasileiros.

Por fim, sobre o Tratado de Amizade e Consulta, JK afirmou que "procurarei apressar a regulamentação desse instrumento diplomático que está presentemente confiado a uma comissão interministerial. Farei isso para que os portugueses gozem 
de todos os direitos dos brasileiros, com as únicas restrições, é claro, expressas na constituição brasileira". ${ }^{7}$

A segunda viagem de JK a Portugal, já caminhando para o final de seu mandato, foi em agosto de 1960, quando das festas henriquinas. Convidado pelo governo português para participar como co-anfitrião - direito a ajudar a receber os demais chefes-de-Estado - das celebrações do V Centenário da morte do Infante D. Henrique, Juscelino teve de vencer resistências por parte dos nacionalistas que se opunham a que o presidente prestigiasse o governo português, ainda detentor do status colonial. Álvaro Lins, ex-embaixador do Brasil em Lisboa, criticou o caráter de co-anfitrião dado à viagem, já que nessa condição o mandatário brasileiro fará as honras da casa e não as receberá, caso tivesse ido como visitante. "Por outro lado, como co-anfitrião, o Presidente do Brasil, chefe-de-Estado de um país democrático, irá ser, simbolicamente, moralmente, figuradamente o chefe-de-Estado também da ditadura portuguesa ..." ${ }^{8}$ E afirma que o governo português se valerá da viagem de nosso presidente para fortalecer-se internamente, já que sua legitimidade começa a ser contestada, como também para reforçar sua estratégia colonialista.

Tanto é verdade que Salazar cuidou pessoalmente dos detalhes dessa viagem para que o envolvimento do presidente brasileiro se desse de forma completa. As visitas, os discursos, o doutoramento em Coimbra, os desfiles em carro aberto, enfim, todos os passos de JK foram meticulosamente calculados. Salazar chega ao extremo de determinar a cidade e o local onde o presidente e sua comitiva deveriam pernoitar em seus deslocamentos internos. E sempre acompanhado pelo presidente figurativo Américo Tomás. ${ }^{9}$

Antes da viagem, a oposição portuguesa fez publicar uma "Carta Aberta ao Presidente Kubitschek de Oliveira”, distribuída clandestinamente em Lisboa, na qual alertava o visitante de que no país anfitrião vivia-se um regime ditatorial fascista com mais de três décadas de existência. E passava a relatar algumas das arbitrariedades cometidas por Salazar, chamando a atenção para o fato de que "esse governo impopular pretende aproveitar-se da visita do presidente da República do Brasil para se legitimar e se lavar do mais absoluto descrédito em que caiu perante os portugueses e perante o mundo". E terminava recomendando ao mandatário brasileiro que buscasse estreitar o contato com o povo português, que, além de amar o Brasil, busca ardentemente a sua liberdade". ${ }^{10}$

A estada da comitiva presidencial brasileira foi marcada por uma apoteose ímpar. Desde a sua chegada até a partida, foram homenagens pomposas, solenes e populares para caracterizar a seriedade e a solidez das relações entre os dois países e ao mesmo tempo a afetividade histórica que os unia através de laços indestrutíveis. Como afirmou Kubitschek, "não temos apenas relações diplomáticas ou cordiais, mas ligações de família. Somos um caso particular no Mundo". ${ }^{11}$ 

português

Calvet de Magalhães chega a lamentar que uma proposta de emenda constitucional que permitiria a reeleição do presidente brasileiro não tivesse prosperado e que, portanto, Juscelino não pudera postular um segundo mandato, o que teria sido relevante para Portugal, já que as relações entre os dois países foram tão amistosas. ${ }^{12}$

Por outro lado, Salazar, que não costumava desamparar os amigos quando saídos do poder, protestou pela atitude da emissora nacional e da Rádio e Televisão Portuguesa (RTP) por não terem dado uma cobertura à visita que Juscelino Kubitschek, já na condição de ex-presidente, fizera ao Fundão, em 1963.

\section{Razões do apoio de JK ao colonialismo português}

Várias razões de diversas ordens levaram JK a formular, em relação a Portugal, uma política externa contraditória aos objetivos de sua Operação PanAmericana. Princípios como a autodeterminação, a não-intervenção, a soberania, o nacionalismo e a democracia representativa ${ }^{13}$ são deixados de lado para apoiar a estratégia portuguesa da longevidade de seu regime autoritário, assim como da manutenção de seu sistema colonial, atitudes essas desfavoráveis ao Brasil não apenas política, cultural e socialmente, mas também no aspecto econômico.

Quatro razões, a meu juízo, levaram JK a apoiar o império colonial português na Quarta Comissão das Nações Unidas, onde se discutia o processo de descolonização. A primeira delas é de ordem ideológica. Juscelino atribuía ao subdesenvolvimento econômico a grande razão da entrada do comunismo internacional na América Latina. Em Washington, em visita ao Senado, afirmou que "para combater as idéias extremistas em meu país - idéias defendidas por uma escassa minoria - é, sobretudo, necessário elevar o Brasil à altura do seu destino e trabalhar sem descanso para aumentar o nível de vida, como vós fizestes neste país". E reafirmava que somente através do "desenvolvimento e expansão" se poderia eficazmente resolver os problemas sociais. Embora tivesse recebido apoio dos comunistas na eleição presidencial, respondeu a um jornalista estadunidense, ser no Brasil o voto obrigatório e secreto e que não fizera qualquer acordo com tal partido, defendendo inclusive a sua não-legalização. ${ }^{14}$

Enquanto Kubitschek agradava ao governo de Washington em sua recente passagem pelos Estados Unidos ao reafirmar seu alinhamento ideológico no contexto da Guerra Fria, também tivera pronta repercussão naquela capital o discurso proferido por Salazar no dia 19 de janeiro de 1956 no qual apresentara uma "arraigada posição anticomunista, que tornou Portugal um baluarte da defesa ocidental contra as intromissões revolucionárias dos comunistas".

Se Juscelino defendia uma política ocidental sob a hegemonia dos Estados Unidos, para Salazar "a Europa e a América são o Ocidente, tendo-se em conta que 
a primeira é o berço de uma civilização que tem dirigido os destinos mundiais" e a segunda dela é originária. ${ }^{15}$

Tão boas eram as relações entre os dois governos (Brasil e Portugal) que os Estados Unidos recorreram a JK para que este conseguisse junto a Salazar uma concessão de asilo ao ditador Fulgêncio Batista, um agente tensionador na região do Caribe após a sua queda do governo cubano. O regime salazarista atendeu ao pedido, mas fez com que o mesmo constasse em um documento para futuras negociações. E Batista foi para a paradisíaca Ilha da Madeira.

A segunda razão é de ordem afetivo-histórica. A tese da afetividade histórica, durante o governo de $\mathrm{JK}$, assume um discurso nacionalista com um conteúdo ideológico conservador que se ajusta perfeitamente à estratégia do regime salazarista. Tanto os cosmopolitas como os nacionalistas brasileiros assimilam a afetividade histórica por diferentes razões. Enquanto os primeiros aproveitam para se aproximar eleitoralmente das camadas sociais influenciadas pelas ativas comunidades portuguesas espalhadas pelo país e apoiar a manutenção das colônias ultramarinas dentro de uma estratégia de proteção do Atlântico Sul diante do avanço do comunismo internacional, os segundos aceitam o discurso da afetividade histórica como uma variante inofensiva das elites brasileiras, já que sua principal preocupação se dá nas relações do Brasil com os Estados Unidos e não com Portugal. Obviamente que os nacionalistas condenavam, sem muita ênfase, o regime autoritário salazarista, porém, essa complacência só se rompe com o caso do asilo ao general Humberto Delgado ${ }^{16}$ e a intransigência do governo português em concedê-lo. A partir daí, o discurso da afetividade histórica passa a ser denunciado como contemporizador de uma aliança espúria entre os governos brasileiro e português. ${ }^{17}$

Quando convidado para visitar Lisboa, ainda na condição de presidente eleito, Kubitschek exaltou o aspecto afetivo-histórico ao dizer que "visitar Portugal é para o brasileiro rever o próprio lar. A minha visita é a visita de um filho ao pai. É com emoção que mais uma vez vou contemplar os velhos monumentos que assinalam na História do Mundo a hora solar do povo lusitano. Em nome do Brasil, saúdo a raça heróica que descobriu a minha pátria, abrindo para o mundo uma imensa forja de trabalho e civilização". ${ }^{18}$ E uma vez em Portugal exalta o destino comum das duas nações, já que se torna "difícil saber onde termina a história de Portugal e começa a nossa vida, onde os nossos Reis se separaram e depois são os mesmos".

Por ocasião das festas henriquinas, o Diário de Notícias deu um amplo destaque ao presidente Kubitschek, sua família e sua comitiva, já que o mandatário brasileiro participava na condição de co-anfitrião. As relações luso-brasileiras ocuparam o espaço principal desse jornal durante dez dias. A saudação do ministro 

português

das Relações Exteriores do Brasil, Horácio Lafer, expressa bem o clima afetivohistórico dos dois governos:

A visita a Portugal do presidente Kubitschek, no momento em que o grande povo lusitano comemora o V centenário da morte do infante D. Henrique, é mais uma demonstração dos fortes e indissolúveis laços de amizade que unem os povos brasileiro e português. É, por assim dizer, não o encontro de duas pátrias, pois Brasil e Portugal estarão sempre unidos, mas a junção das homenagens e do entusiasmo de dois grandes povos a um dos seus mais gloriosos antepassados. O povo brasileiro sentese orgulhoso em poder mandar o seu presidente da República (sic) a Lisboa, como seu máximo representante, ao berço da sua civilização, para, com os portugueses, reviver os brilhantes dias da nossa história, da nossa cultura, da nossa glória. Em vésperas de pisar o solo da pátria de Pedro Álvarez Cabral, de D. João, do Pe. Antônio Vieira e de tantos outros nomes ilustres da raça lusa que tanto deram ao Brasil, eu saúdo o povo português. ${ }^{19}$

A entrevista concedida ao Diário de Notícias por JK também exalta a afetividade entre os dois países: "encaro com o maior otimismo o futuro da comunidade luso-brasileira [porquanto] os laços que unem a mãe a um filho jamais se podem quebrar". Ao se referir sobre as relações políticas, disse que "o Tratado de Amizade e Consulta corresponde às mais íntimas aspirações dos dois povos". ${ }^{20}$

$\mathrm{Na}$ realidade, essa recepção apoteótica ao presidente brasileiro tinha pelo menos três objetivos principais: a) o da gratidão pelo apoio concedido a Portugal nas Nações Unidas, já que naquele organismo internacional o Brasil chegara a prejudicar os seus próprios interesses em favor dos da metrópole colonial; b) o da consolidação de uma política externa brasileira que fosse favorável à estratégia ultramarina portuguesa e que os futuros governos se sentissem impossibilitados de alterar; c) o da exemplificação ao mundo de mais um sucesso de uma colonização lusitana; d) o da solução parcial dos problemas econômicos portugueses, caso alguns países utilizassem a arma do mercado para pressionar Portugal na direção da descolonização.

A terceira razão do apoio político brasileiro ao império colonial português é de ordem eleitoral. As comunidades portuguesas, nos mais diversos países do mundo, eram estimuladas pela diplomacia de Lisboa a se organizarem para defender os seus interesses e os de Portugal. Tanto que não apenas os estatutos, mas até estratégias de atuação, eram submetidos ao Palácio das Necessidades, que por sua vez tudo fazia chegar ao presidente do Conselho de Ministros. Muitas dessas comunidades dispunham de veículos de comunicação, hospitais beneficentes, clubes recreativos e de futebol, sistema de lobbies, concessão de títulos honoríficos 
e outros mecanismos para envolver as autoridades do país no apoio ao governo lusitano.

A emigração portuguesa funcionava como uma espécie de distensão para as crises internas do regime salazarista. A economia, ainda voltada para o agrarismo, não absorvia toda a mão-de-obra que chegava ao mercado. Desse modo as colônias ultramarinas, bem como um conjunto de países, entre eles o Brasil, suportavam essa carência econômica. De acordo com o Censo de 1950, viviam no Brasil 310.261 portugueses, dos quais naturalizados brasileiros somente 26.595 , enquanto o número de brasileiros em Portugal era de 3.780. Já em 1954 a colônia portuguesa é calculada em 615.400 pessoas, das quais 300.000 pertencem ao Distrito Consular do Rio de Janeiro e 250.000 ao de São Paulo ${ }^{21}$. Este número é muito significativo se levarmos em conta que o montante de portugueses emigrados no mundo estava em torno de 900.000.

Em maio de 1957 o deputado Celso Peçanha apresentou à Câmara Federal um Projeto de Lei que concedia o direito de voto aos cidadãos portugueses residentes no Brasil, desde que preenchendo determinadas condições, tais como morar no país há mais de cinco anos, ter como cônjuge um brasileiro ou uma brasileira, viver há mais de dez anos, mesmo sendo solteiro ou ter filhos nascidos no país. Caso fosse aprovado o referido projeto, ter-se-ia uma equiparação de direitos políticos entre brasileiros e portugueses, ressalvadas algumas exceções, como a de votar mas não ser sufragado. Segundo o Instituto Brasileiro de Geografia e Estatística (IBGE), mais de 300.000 portugueses estariam em condições de votar, o que daria um grande poder político à já organizada comunidade lusitana.

Essas comunidades, na sua expressiva maioria, votavam nos candidatos que se posicionassem favoráveis à defesa dos interesses salazaristas no além-mar. Chegavam a se manifestar publicamente, por meio de anúncios em jornais, pedindo votos em favor de determinadas pessoas que haviam apoiado as comunidades luso-brasileiras. Como possuíam um espírito de corpo muito forte e grande parte dos seus integrantes trabalhava no comércio mantendo contato diário com outras pessoas, Juscelino tinha os olhos postos em tais comunidades e nos seus comendadores. Como tencionava voltar a candidatar-se à Presidência em 1965, era muito importante manter durante todo o seu governo um bom relacionamento com o regime salazarista.

As comunidades portuguesas também trabalhavam muito ativamente na difusão da cultura lusitana por meio da divulgação de seus autores clássicos, de sua ideologia expansionista marítima, de suas datas históricas, de seus costumes, de suas danças, de suas músicas e de sua culinária. A fidelidade à pátria distante se manifestava, muitas vezes, de forma emocional e dramática ao proclamar que, "quando Portugal ou os seus governantes sofrem qualquer ataque, imediatamente 
se apresentam, prontos para sua defesa em todas as circunstâncias. Tem sido sempre assim e assim será sempre. Que não nos esqueçamos nunca que temos de conservar a qualquer preço, incluindo a própria vida, a histórica herança que os nossos maiores nos legaram e que fizeram a golpes de destemor e de audácia" 22 . E sacralizavam a idéia de pátria e as figuras do governo e do embaixador. Sempre que acontecia alguma catástrofe pública ou data significativa, lançavam mão de campanhas publicitárias passando a imagem de uma solidariedade com os menos aquinhoados. O Natal dos flagelados pela estiagem do Nordeste ou dos soldados portugueses em guerra contra os africanos era lembrado com regularidade.

Muitas dessas comunidades se apresentavam com nomes luso-brasileiros, mostrando uma integração com a cultura e a história do novo país, tendo no entanto os mesmos objetivos de sempre: angariar a simpatia e o apoio em favor dos interesses do governo português.

Isso as credenciava como instituições preocupadas com o bem comum da sociedade e mudava a sua imagem não muito favorável durante a primeira fase (1822-1900) das relações entre os dois países.

A quarta razão é de ordem religiosa. A Igreja Católica, de modo especial a sua alta hierarquia, viveu um longo período de ajuda mútua com o Estado Novo português. O cardeal patriarca de Lisboa - D. Manuel Gonçalves Cerejeira -, que fora colega de Salazar no Seminário Diocesano de Viseu (1900-1908), embora denominasse tais relações de harmoniosas, desempenhou um papel fundamental nesse pacto de dominação cívico-religiosa. Mais de uma vez, ambos os príncipes, um da Igreja Católica e o outro da Presidência do Conselho de Ministros, tentaram mostrar alguma divergência pública exatamente para diluir a acintosa união entre os dois poderes. No entanto, não é isso o que demonstram os documentos trocados entre eles. Mesmo quando discordavam de métodos e conteúdos, o fascínio pela manutenção do poder os unia.

Em uma missiva dirigida a Salazar, quando este estrategicamente se retirara para seu povoado natal ao término da Segunda Guerra Mundial e mostravase publicamente abatido, Cerejeira encaminha em anexo um trecho de uma carta da Irmã Lúcia - a vidente de Fátima ${ }^{23}$-, comentando que aquelas referidas linhas deverão "levar-te muita consolação e confiança", já que se trata de uma "indicação divina" (sic). Diz o texto da Irmã Lúcia que "Salazar é a pessoa por Ele (Deus) escolhida para continuar a governar a nossa Pátria, (. . .) a ele é que será concedida a luz e graça para conduzir o nosso povo pelos caminhos da paz e da prosperidade". E continua a explicitar que "é preciso fazer compreender ao povo que as privações e sofrimentos dos últimos anos não foram efeito de falta alguma de Salazar, mas sim provas que Deus nos enviou pelos nossos pecados"24.

Esse pacto de dominação interessava a ambos. Se à Igreja Católica Salazar 
oferecia a reposição de um estatuto perdido na I República (a Concordata), a restauração de um ambiente propício aos tradicionais valores cristãos e o fim do anticlericalismo do regime anterior, por sua vez esta mesma Igreja garantia ao presidente do Conselho de Ministros bases políticas, sociais e ideológicas para a fundação e manutenção do Estado Novo. Essa colaboração mútua, instrumentalizada de acordo com os interesses de cada um deles - Salazar necessitando do apoio político dos católicos, e Cerejeira defendendo-se de um possível regresso ao anticlericalismo -, cria uma interdependência entre os dois poderes. Isso serviu durante quase 40 anos à propaganda do nacional-catolicismo, esmagando por um lado a oposição ao regime e por outro a luta contra os privilégios eclesiásticos.

Tanto que o cardeal celebra um solene Te Deum pelas bodas de prata da entrada do presidente do Conselho para o governo, e por sua vez o premier, juntamente com todo o seu alto escalão, participa das comemorações dos 25 anos de cardinalato do patriarca de Lisboa.

As intervenções do governo português em relação à atuação da Igreja Católica se deram quase sempre tendo por referência a questão colonial. O subvencionamento do culto e do clero pelo Estado, assim como a expulsão de padres e freiras que questionassem o processo colonial, são apenas dois exemplos de como o regime salazarista mantinha um severo controle dos trabalhos religiosos no país e no ultramar. Franco Nogueira, ao fazer um relato de conversa que tivera com o Núncio Apostólico Mons. Fustenberg, comenta que perguntara ao representante da Santa Sé que destino teria sido dado a um memorandum entregue na Secretaria do Concílio por organizações terroristas anti-portuguesas "contendo as mais atrozes acusações e alegações contra Portugal". Ao que o embaixador do Vaticano respondeu prontamente que, "apenas soubera do caso, se precipitara para a Secretaria do Concílio e sustara a circulação do memorandum". E concluiu dizendo que "só uns três ou quatro prelados tiveram conhecimento do fato. Tudo se passara discretamente e o caso não tivera a menor repercussão no Concílio"25.

Nesse mesmo relato de conversa o embaixador do Vaticano trata do assunto do Bispo do Porto, contando ao ministro dos Negócios Estrangeiros que se havia empenhado junto àquele Prelado, como também o fizera o cardeal Cerejeira, com a finalidade de que o mesmo renunciasse a sua diocese. Como não conseguisse demover D. António Ferreira Gomes, que pelo contrário continuava com sua atuação política e ademais muito bem informado de tudo o que acontecia nas ditaduras ibéricas, falou que o mesmo dava a impressão de que não "se acha[va] em estado perfeitamente normal". Ao que Salazar sublinhou com seu lápis azul esta afirmativa. Portanto, é o próprio representante oficial do Vaticano a cunhar de demente um de seus bispos que ousara questionar o autoritarismo do governo, no afã de agradar ao regime salazarista. 

português

Por fim, Nogueira falou ao Núncio que a "descolonização", tal como estava sendo praticada, significaria a morte do cristianismo na África. E a verdade histórica "é que só pela mão do Ocidente se tem o Cristianismo expandido pelo Mundo".

Em outra conversa com o embaixador do Vaticano, Franco Nogueira reclama de uma foto onde aparecem três pessoas conversando, sendo uma delas o Arcebispo de Leopoldville, a outra o Núncio Apostólico no Congo e, por fim, Holden Roberto, este último considerado um terrorista pelo governo de Lisboa. Ao que o diplomata do Vaticano, ao olhar novamente a foto, comentou: "em todo o caso, repare que os Bispos mostram a maior circunspecção".

Esse relato de conversa, aparentemente sem grande importância, revela o grau de dependência e servilismo do embaixador do Vaticano diante do chefe da diplomacia portuguesa. Na verdade, a Santa Sé apreciava o trabalho de Salazar por considerá-lo um "homem providencial que viera para salvar Portugal do abismo em que ia despenhar-se".

Foi ao mais alto representante da hierarquia dessa Igreja conservadora portuguesa - o cardeal Cerejeira - que Juscelino fez dois convites: a) para que assumisse a função de seu apresentante, isto é, padrinho na cerimônia de concessão do título de doutor honoris causa na Faculdade de Direito na Universidade de Coimbra, e b) para que celebrasse a missa inaugural de Brasília.

Quando desembarcou no Rio de Janeiro para dar seguimento ao segundo convite, foi recebido como chefe de Estado por Kubitschek, já que representava oficialmente o Vaticano. Não apenas desfilou em carro aberto pelas ruas da cidade ao lado do presidente como também "repicaram os sinos do Rio para o Cardeal Cerejeira". Por sua vez, o Príncipe da Igreja exalta o Brasil e JK, diz que "este é que merecia ter as mãos beijadas", numa espécie de retribuição aos mesmos elogios feitos algum tempo antes pelo cardeal Câmara a Salazar, quando de sua visita a Lisboa pela inauguração do monumento a Cristo-Rei.

Em Brasília, JK homenageia o Patriarca de Lisboa e diz que "olhamos para Vossa Eminência com a mesma filial devoção e o mesmo calor com que os criadores do mundo de língua portuguesa - os mesmos que abriram as portas dos mares nunca dantes navegados e estenderam a Fé de Cristo - contemplavam os Pastores missionários que tornaram completa a conquista das terras com as conquistas das almas".

Esse discurso religioso conservador de JK aparece em um outro momento, quando agradecia as palavras do presidente Américo Tomás na sua visita a Portugal. Juscelino avaliava que "a grande crise do Ocidente consiste na descrença, que dia a dia vai aumentando, da fé nos valores que nós próprios defendemos. Não há causa que subsista sem que haja fé nos seus postulados, nas suas finalidades, nos seus fundamentos". 
Portanto, as relações do presidente JK com essa Igreja portuguesa conservadora inevitavelmente complementaria uma relação no mesmo nível com o regime, já que ambos tinham uma estratégia comum de dominação. Além do mais, a própria esposa de JK, Dona Sara, estimulava tais ligações, pois em sua visita a Portugal, mais especificamente a Fátima, para pagamento de promessas relativas à saúde de sua filha, afirmava que fora uma honra estar com Salazar, podendo observar "que se trata duma excepcional personalidade política, como é opinião de meu marido. É um grande estadista". Tudo isso foi amplamente divulgado pelos jornais e aproveitado para estreitar os laços entre os dois países.

\section{Considerações finais}

A análise das relações entre o governo de Juscelino Kubitschek e o regime salazarista leva-me a apontar um conjunto de incongruências por parte da administração brasileira. A primeira delas se encontra no apoio dado ao status quo colonial português. Isso porque, se desde a posse na Presidência da República até meados de 1958 a política externa de JK manteve a linearidade dos dois governos anteriores, de cunho conservador, a partir de maio de 1958 assume uma conotação nacionalista, voltada inteiramente para a realização das metas desenvolvimentistas do país. Nessa conjuntura o presidente lança a Operação Pan-americana, rompe com o Fundo Monetário Internacional (junho de 1959) e, contraditoriamente, apoia a política colonialista portuguesa, ratificando, inclusive, o Tratado de Amizade e Consulta entre os dois países. A grande pergunta é: que motivos teriam levado o presidente a adotar uma política externa com características progressistas em relação ao desenvolvimento de seu país e de sua região e simultaneamente uma estratégia colonialista diante dos interesses portugueses na África e na Ásia?

Álvaro Lins chega a questionar o que restará da Operação Pan-Americana com JK integrado ao salazarismo. E também pergunta o que sobrará dessa mesma Operação com os atos de política externa a serem assinados em Lisboa por Juscelino, que até há pouco se havia autoproclamado um americanista, fiel aos compromissos do Brasil e da região perante quaisquer outras relações internacionais.

A segunda contradição da política externa de JK está na regulamentação do Tratado de Amizade e Consulta, desvantajoso para os planos progressistas da política externa brasileira, como também oneroso para alguns interesses dentro de nosso próprio território. Seu artigo $1^{\circ}$, por exemplo, afirma que as partes concordam que farão consultas sobre os problemas internacionais de seu manifesto interesse comum. Assim, o governo português, que começa a ser questionado nos organismos multilaterais por sua postura colonialista, sente-se no direito de saber antecipadamente a posição brasileira e desse modo usar de estratégias para 
influenciá-la antes de qualquer votação internacional. Era o que fazia a diplomacia portuguesa, sediada no Rio de Janeiro, através da corrente lusófila do Itamaraty. Esse artigo se contrapõe ao espírito da Operação Pan-americana, que buscava uma política externa latino-americanista, nacionalista, anticolonialista, soberana e independente.

A terceira contradição se refere à Declaração de Santiago, firmada pelo governo brasileiro, na qual, entre outros propósitos, subscreve que é do "anseio geral dos povos americanos de viver em paz, ao amparo de instituições democráticas alheias a toda intervenção e a toda influência de caráter totalitário"; "que a existência de regimes antidemocráticos constitui uma violação dos princípios em que se funda a Organização dos Estados Americanos e um perigo para a convivência solidária e pacífica no hemisfério" e que "a perpetuação no Poder, ou o exercício deste sem prazo determinado e com manifesto propósito de perpetuação, são incompatíveis com o exercício da Democracia”. No entanto, em Portugal vive-se uma ditadura, caracterizada pela ideologia corporativista do Estado Novo, com uma Comissão de Censura, com uma Polícia Política, com a ausência de partidos políticos legalizados e com milícias de Estado armadas.

A quarta contradição diz respeito à dependência a que o Brasil se impõe em relação ao Pacto Ibérico, já que os regimes autoritários de Franco e Salazar tinham subscritos acordos com o objetivo de enfrentar mutuamente os novos ventos democratizantes do pós-guerra. Isso opõe-se radicalmente à política externa da Operação Pan-Americana e à própria inserção do país na Segunda Guerra Mundial.

O tradicionalismo em relação a Portugal - diz Claudio Bojunga - estava em contradição frontal com o desenvolvimentismo, cujos interesses seriam mais satisfeitos pela remoção de vínculos coloniais que só beneficiavam a diplomacia salazarista.

Finalmente, o governo brasileiro, que buscava uma liderança regional na América Latina para poder negociar com mais força diante dos Estados Unidos, debilita-se em sua região, ao apoiar na Europa os regimes salazarista e franquista. Cabe ressaltar que naquele momento um grande número de países latino-americanos se opunha aos regimes ditatoriais ibéricos. O México, por exemplo, rompera suas relações diplomáticas com Madrid por conta da Guerra Civil Espanhola. 


\section{BIBLIOGRAFIA}

ALMEIDA, L. F. Uma ilusão de desenvolvimento: nacionalismo e dominação burguesa nos anos JK. Florianópolis: EdUFSC, 2006.

BOJUNGA, C. JK: o artista do impossível. Rio de Janeiro: Objetiva, 2001.

GONÇALVES, W. S. O realismo da fraternidade: as relações Brasil-Portugal no governo Kubitschek. 2 v. Tese de Doutorado em Sociologia, Departamento de Sociologia, Universidade de São Paulo, São Paulo, 1994.

LINS, Á. Missão em Portugal. Lisboa: Centro do Livro Brasileiro, 1974.

RAMPINELLI, W. J. As duas faces da moeda: as contribuições de JK e Gilberto Freyre ao colonialismo português. Florianópolis: EdUFSC, 2004.

RODRIGUES, J. H. Brasil e África: outro horizonte. Rio de Janeiro: Civilização Brasileira, 1961.

SOLA, L.). Idéias econômicas decisões políticas. São Paulo: EdUSP, 1988.

\section{Arquivos}

Arquivo Histórico-diplomático do Ministério dos Negócios Estrangeiros - Lisboa.

Arquivo Nacional da Torre do Tombo - Lisboa.

Arquivo Oliveira Salazar - Lisboa.

Arquivo Histórico do Itamaraty - Rio de Janeiro.

Arquivo Negrão de Lima - Rio de Janeiro.

\section{NOTAS}

I De acordo com documentos emitidos pela embaixada portuguesa no Rio de Janeiro, aparecem como lusófilos, entre outros, os diplomatas Pio Correia, Frank Moscoso, Donatello Grieco, Odette de Carvalho e Souza, Francisco Negrão de Lima e Assis Chateaubriand. Enquanto Fontoura chegara a ofertar à Legião Portuguesa - milícia salazarista - uma bandeira brasileira, Negrão de Lima, chamado ao Rio para consultas, avistou-se duas vezes com o ministro dos Negócios Estrangeiros a fim de preparar-se para as respostas a serem dadas a seu chefe imediato, o chanceler Afonso Arinos. Fontoura e Negrão, à época desses fatos, eram embaixadores brasileiros em Lisboa.

2 Ofício da embaixada de Portugal (confidencial). Convenção de Amizade e de Consulta luso-brasileira, Ministério dos Negócios Estrangeiros (MNE), 24 de jul. 1951.

3 RODRIGUES, J. H. Brasil e África: outro horizonte. Rio de Janeiro: Civilização Brasileira, |96 | p. 3 | 4.

4 Nacionalistas e cosmopolitas eram correntes político-ideológicas que atuavam no interior do aparelho estatal, como também disputavam duramente a política externa do país. Essa classificação foi formulada 


\section{A política internacional de JK e suas relações perigosas com o Colonialismo português}

originalmente por Hélio Jaguaribe e, mais tarde, utilizada por diversos autores, entre eles SOLAS, L. Idéias econômicas decisões políticas. São Paulo: Edusp, 1998.

5 Portugal no Estrangeiro. Arquivo Nacional da Torre do Tombo (AN-TT); Arquivo Oliveira Salazar (AOS), II nov. 1995.

6 KUBITSCHEK, J. Diário de Notícias, Lisboa, p. 5, 23 jan. 1956.

7 lbidem.

8 LINS, Á. Missão em Portugal. Lisboa: Centro do Livro Brasileiro, 1974, p. 334.

9 Visita a Portugal de JK. AN-TT/AOS.

10 Carta Aberta ao Presidente Kubitschek de Oliveira. O Estado de S. Paulo, 30 abr. 1960 (publicada em vários jornais).

I I KUBITSCHEK, J. Discurso. Lisboa, 7 ago. 1960.

12 MAGALHÃES, José Calvet de. Entrevista concedida ao autor. Lisboa, 29 mar. 2001.

13 Sobre estes temas ver o livro de ALMEIDA, Lúcio Flávio de. Uma ilusão de desenvolvimento: nacionalismo e dominação burguesa nos anos JK. Florianópolis: Editora da UFSC, 2006.

14 KUBITSCHEK, J. Diário de Notícias. Lisboa, p. 5, 6 jan. 1956.

I 5 SALAZAR, O. Apontamentos sobre a situação internacional. Luanda, Imprensa Nacional de Moçambique, 1956, p. 5.

$16 \bigcirc$ general Humberto Delgado, desafiando a ditadura do Estado Novo, apresentou-se como candidato à Presidência da República, em 1958. Realizou grandes comícios, como o do Porto, do qual participaram cerca de 200 mil pessoas. O governo, acusado de fraudar o processo eleitoral, se viu forçado a reconhecer que $22,5 \%$ da população não aprovaram o salazarismo.

17 GONÇALVES, W. da S. O realismo da fraternidade: as relações Brasil-Portugal no governo Kubitschek. 1994. 2. V. Tese (Doutorado em Sociologia). Universidade de São Paulo, p. 37I-372.

18 KUBITSCHEK, J. Diário de Notícias, Lisboa, p. I-5 jan. 1956.

19 LAFER, H. Ao povo português. Diário de Notícias, Lisboa, p. I-3, ago. 1960.

20 KUBITSCHEK, J. Entrevista. Diário de Notícias, Lisboa, p. I e 2,5. Ago. 1960.

21 Boletim Anual da Junta da Emigração - 1954, Ministério do Interior, Casa Nun'Álvaraes Gouveia, Lisboa.

22 LAGE, Aventino Fernandes da Silva (discurso do presidente da Federação das Associações Portuguesas). A fidelidade da colônia portuguesa à pátria distante. Voz de Portugal, Rio de Janeiro, 22 out. 1961.

23 A diplomacia portuguesa procurou dar visibilidade internacional a Fátima, principalmente a partir do final dos anos 1930, já que o culto a ela se tornara vantajoso para o regime salazarista. A Senhora da Cova da Iria passara a ser, então, o escudo contra o perigo vermelho que rondava Portugal, quer por meio da Guerra Civil Espanhola (em 13 de maio de 1938 uma grande peregrinação celebra a vitória dos franquistas), quer através do segundo conflito mundial (Portugal se mantivera oficialmente em posição neutral); passara a ser também a padroeira da Guerra Fria na luta contra uma Rússia atéia; a protetora dos soldados que partiam para a guerra colonial contra a África; e a abençoadora do Estado Novo nacionalcatólico. Veja-se a respeito REIS, Bruno Cardoso et alii. Fátima e o poder. Revista de História, Lisboa, ano xxii, n. 29, p. 14-46, out. 2000. Quanto à forte exploração anticomunista de Fátima, o próprio Papa João XXIII se manifestara contrário, em um encontro com o embaixador português António Faria, no Vaticano. Ao relatar a conversa para seu chefe imediato em Lisboa, diz o diplomata: " [O] Santo Padre falou de Fátima e aludiu [a] conveniência [de] não se tentar fazer dizer Irmã Lúcia, atualmente [no] convento [de] Coimbra, mais do que ela estaria em condições de dizer (isto a propósito [de] referências por vezes feitas a eventuais atitudes [da] Rússia relacionadas com pretensas declarações em que se mencionava [a] data [de] 1960) matéria esta muito delicada que exigia toda prudência". Telegrama da Embaixada Portuguesa no Vaticano (confidencial). Ministério dos Negócios Estrangeiros (MNE), P.E.A, M 288, 2 P, Proc. 332,52, N. G. 4.402, de 7 de julho de 1961 .

24 AN-TT/AOS/CP-47/fl. 94 v, de 13 de novembro de 1945.

25 Conversa com o Núncio Apostólico (secreto). AN-TT/AOS/CO/U-30B, 10 de dezembro de 1962. 